\title{
MONITORAMENTO TECNOLÓGICO DO MEL E TECNOLOGIAS CORRELATAS ATRAVÉS DO ESTUDO EM DOCUMENTOS DE PATENTES DEPOSITADOS NO BRASIL (1984-2011)
}

\author{
Bruna Aparecida Souza Machado ${ }^{1}$; Aline Silva Costa ${ }^{1}$; Aline Rabello Costa Alves ${ }^{1}$; Luana de \\ Oliveira Melo Naponucena ${ }^{1}$; Silmar Baptista Nunes ${ }^{1}$; Marcelo Andres Umsza-Guez ${ }^{1}$; Francine \\ Ferreira Padilha ${ }^{2}$ \\ ${ }^{1}$ Serviço Nacional de Aprendizagem Industrial - SENAI - Salvador/BA - Brasil e Universidade \\ Federal de Sergipe - UFS - São Cristóvão/SE - Brasil (brunam@fieb.org.br) \\ ${ }^{2}$ Universidade Tiradentes - UNIT - Aracaju/SE - Brasil
}

\section{RESUMO}

Diante do aumento no interesse do mel pelas indústrias de alimentos e farmacêutica, decorrente principalmente das suas propriedades funcionais e medicinais, bem como de suas novas possibilidades de aplicação, o objetivo deste estudo foi realizar um monitoramento tecnológico para avaliar o panorama nacional da proteção de processos e produtos relacionados a esta matéria-prima. A pesquisa foi realizada na base de dados on line do Instituto Nacional de Propriedade Industrial (INPI), visto que abrange todas as patentes depositadas e publicadas no Brasil. Foram selecionados 142 documentos para compor o escopo dos resultados, considerados relevantes para a pesquisa. A partir do mapeamento tecnológico realizado neste estudo, percebe-se que essa matriz está sendo utilizada para o desenvolvimento de produtos e processos em diferentes áreas tecnológicas e que o Brasil ainda é um país de pouco interesse para a proteção da tecnologia na área pesquisada, evidenciado através do pequeno número de patentes de não residentes.

Palavras Chave: mel, produtos apícolas; patentes; prospecção.

\section{ABSTRACT}

Given the increasing interest in honey by food and pharmaceutical industries, particularly its associated functional and medicinal properties that yield new uses, the aim of this study was to perform the technological assessment of the national protection landscape, process and products related to honey. The research was conducted in the online database of the National Institute of Industrial Property (INPI), since it covers all patents filed and published in Brazil. The scope selected 142 documents considered as relevant. It was clear that this matrix is being used to develop products and processes in different technological areas. Brazil is still a country of little interest for the protection of this technology, evidenced by the small number of non-resident patent.

Key words: honey; bee products; patents; technologic assessment.

Área tecnológica: Tecnologia de alimentos; Produtos Naturais e Animais.

Cadernos de Prospecção - ISSN 1983-1358 (print) 2317-0026 (online), 2013, vol.6, n.1, p.45-55.

D.O.I.: http://dx.doi.org/10.9771/S.CPROSP.2013.001.006 


\section{INTRODUÇÃO}

O mel é um produto das abelhas melíferas, produzido a partir do néctar das flores ou das secreções procedentes de partes vivas das plantas ou de excreções de insetos sugadores de plantas que ficam sobre partes vivas de plantas, que as abelhas recolhem, transformam, combinam com substâncias específicas próprias, armazenam e deixam madurar nos favos da colmeia (BRASIL, 2000). O mel é constituído por diferentes açúcares, predominando os monossacarídeos glicose e frutose. Apresenta também teores de proteínas, aminoácidos, enzimas, ácidos orgânicos, substâncias minerais, pólen e substâncias, como sacarose, maltose, malesitose, outros oligossacarídeos (incluindo dextrinas), além de pequenas concentrações de fungos, algas, leveduras e outras partículas sólidas resultantes do processo de obtenção do mel (CODEX STANDARD FOR HONEY, 2001).

A importância do mel na nutrição humana não se limita apenas à sua característica adoçante, quando pode ser usado como excelente substituto do açúcar refinado de cana de açúcar, à base de sacarose. É prontamente absorvido pelo organismo, em virtude de sua composição química, especificamente com os principais tipos de açúcares presentes (frutose e glicose). Deve ser considerado também como alimento de alta qualidade, rico em energia e inúmeras outras substâncias benéficas ao equilíbrio dos processos biológicos de nosso organismo. Principalmente, para crianças e idosos, o mel pode ser um carboidrato mais palatável e mais facilmente absorvido, tendo seu valor calórico, usualmente definido como 3,04 kcal/g (CAMARGO et al., 2006). Além de sua qualidade como alimento, esse produto único é dotado de inúmeras propriedades terapêuticas, sendo utilizado pela medicina popular sob diversas formas e associações com fitoterápicos (PEREIRA et al., 2003). Apesar do mel ser basicamente uma solução saturada de açúcares e água, seus outros componentes, aliados às características da fonte floral que o originaram, lhe conferem um alto grau de complexidade. Estudos identificaram 181 diferentes substâncias no mel, algumas não encontradas em nenhum outro produto (CRANE, 1980).

O Brasil possui um clima tropical, com ampla, vasta e variada vegetação, sendo considerado um país com forte potencial para a produção dos produtos apícolas. Atualmente o Brasil desponta como o $11^{\circ}$ mais importante produtor mundial e o $5^{\circ}$ em exportação. Em Agosto de 2012 foram exportadas 1.364 toneladas de mel, gerando uma receita de US\$ 4,2 milhões. De acordo com o Instituto Brasileiro de Geografia e Estatísticas (IBGE), foram produzidas 38 mil toneladas de mel em 2010. A região Sul foi a maior produtora de mel do país, produzindo 16,53 mil toneladas de mel, representando 43\% da produção total de mel do Brasil. O Nordeste vem logo em seguida, com uma produção de 13,1 mil toneladas de mel. Os cinco maiores produtores de mel do Brasil são Rio Grande do Sul, Paraná, Santa Catarina, Piauí e Minas Gerais, com 60\% da produção. Na Bahia, o município de Ribeira do Pombal é o melhor posicionado no ranking dos municípios produtores de mel ocupando a $6^{\circ}$ posição (SEBRAE, 2012).

Diante do aumento no interesse do mel pelas indústrias de alimentos e farmacêutica, decorrente principalmente das suas propriedades funcionais e medicinais, bem como de suas novas possibilidades de aplicação, o objetivo deste estudo é realizar um monitoramento tecnológico para avaliar o panorama nacional da proteção de processos e produtos relacionados a esta matéria-prima animal, relacionando os documentos de patentes depositados por país de origem, a evolução anual de depósito, as áreas de proteção dessa tecnologia, bem como estabelecer o interesse internacional de proteção dessa tecnologia no Brasil através da análise de pedidos de patentes de não residentes. Ressalta-se que os estudos de prospecção tecnológica ou mapeamentos tecnológicos podem ser definidos como um meio sistemático de mapear desenvolvimentos científicos e tecnológicos futuros

Cadernos de Prospecção - ISSN 1983-1358 (print) 2317-0026 (online), 2013, vol.6, n.1, p.45-55.

D.O.I.: http://dx.doi.org/10.9771/S.CPROSP.2013.001.006 
capazes de influenciar de forma significativa uma indústria, a economia ou a sociedade como um todo.

\section{DESCRIÇÃO DA TECNOLOGIA}

Atualmente, a cadeia do mel é bastante diversificada. Os produtos consumidos in natura seguem para o mercado por meio dos distribuidores atacadistas e varejistas. Já aqueles consumidos como insumo pelas indústrias entram na composição de diferentes produtos. Os segmentos que mais empregam produtos apícolas como matéria-prima são as indústrias de alimentos, cosméticos e farmacêuticos (PEROSA et al., 2004), isso porque mundialmente o mel é considerado um adoçante natural, fonte de energia e também pela característica medicinal, que confere resistência imunológica, antibacteriana, anti-inflamatória, analgésica, sedativa, expectorante e hipossensibilizadora (GARCIA, 1986; WHITE, 1988). No Brasil, o consumo de mel como alimento ainda é pequeno, em torno de $300 \mathrm{~g} /$ habitante/ano, quando comparado ao consumo de outros países como os Estados Unidos, Comunidade Europeia e África, onde a média de consumo por habitante é de $1 \mathrm{~kg} /$ habitante/ano (AROUCHA et al., 2008).

$\mathrm{O}$ mel pode ser classificado quanto à sua origem em mel floral ou mel de melato (melato). O mel floral é obtido dos néctares das flores, podendo ser classificado em: mel unifloral ou monofloral (quando o produto procede principalmente da origem de flores de uma mesma família, gênero ou espécie e que possua características sensoriais, físico-químicas e microscópicas próprias) ou mel multifloral ou polifloral (obtido a partir de diferentes origens florais). O mel de melato é formado principalmente a partir de secreções de partes vivas das plantas ou de excreções de insetos sugadores de plantas que se encontram sobre elas (BRASIL, 2000). A coloração, aroma e sabor do mel variam de acordo com a sua origem floral, podendo ser quase incolor (oriundo de flores como o assa-peixe), âmbar (flores de laranjeiras), escuro (eucalipto, silvestre) e pardo escuro (trigo sarraceno). Com a idade e conforme a temperatura de estocagem do mel, observa-se escurecimento. O superaquecimento e contaminação com metais também podem escurecer o mel. De maneira geral, o mel escuro tem mais sais minerais do que o mel claro (MENDES et al., 2009).

A Legislação Brasileira, através da Instrução Normativa número 11, de outubro de 2000 (BRASIL, 2000), regulamenta o padrão de qualidade e identidade do mel comercializado, estabelecendo limites que servem para excluir os méis que sofreram algumas práticas de adulteração ou processamento inadequado. Ela regula propriedades como teor de umidade, hidroximetilfurfural, açúcares redutores, sacarose aparente, acidez livre, atividade diastásica, sólidos insolúveis em água, minerais e proíbe o uso de corretivos de acidez, corantes, aromatizantes, espessantes, conservadores e edulcorantes de qualquer natureza, sejam eles naturais ou sintéticos. As análises físico-químicas de méis contribuem na fiscalização de méis importados e no controle da qualidade do mel produzido internamente. Seus resultados são comparados com padrões citados por órgãos oficiais internacionais, ou com os estabelecidos pelo próprio país, protegendo o consumidor de adquirir um produto adulterado (MARCHINI et al., 2000).

\section{METODOLOGIA}

Para a pesquisa da tecnologia protegida ou descrita em documentos de patentes referente ao mel, foi elaborada uma estratégia de busca que combinou os campos da Classificação Internacional de 
Patentes (IPC), nas quais os documentos relativos a esta tecnologia estão classificados, associados a um conjunto de palavras-chave que representam as formas com as quais esta matriz animal poderia ser identificada nos documentos. Com este método de pesquisa, foi realizada a busca em outubro de 2012 na base de dados on line do Instituto Nacional de Propriedade Industrial (INPI), visto que abrange todas as patentes depositadas e publicadas no Brasil, bem como oferece informações importantes a respeito do tipo de depositante, como data de depósito e publicação, país de origem, entre outras. O escopo temporal da pesquisa foi relativo aos depósitos de patentes encontrados até 2011, entretanto, devemos considerar que o número de patentes encontradas parar os anos de 2010 e 2011, não representam o verdadeiro número de depósitos tento em vista o período de sigilo que é de 18 meses. Com o objetivo de aprimorar a pesquisa, identificando apenas os documentos que realmente descrevem a tecnologia protegida, os documentos completos das patentes selecionadas foram obtidos na base on line do Escritório Europeu (Espacenet).

O monitoramento tecnológico realizado através da pesquisa na base de patentes nacional foi elaborado por meio de coleta, tratamento e análise das informações extraídas dos documentos de patentes selecionados. O critério de seleção de documentos se baseou nas informações contidas nos resumos e nos documentos originais, quando estes estavam disponíveis. Foram selecionados todos os documentos de patentes que faziam referência à tecnologia protegida (produtos e processos), bem como tecnologias correlatas (dispositivos) até o ano de 2011. Vale destacar que o termo documento de patente abrange pedidos de patente publicadas, arquivadas ou patentes concedidas no Brasil. Para interpretar as informações da tecnologia patenteada sobre o mel, cada documento selecionado foi analisado e dele extraídas as informações relevantes que descrevem a invenção, e os resultados foram apresentados de acordo com a evolução anual de depósitos, as principais áreas de aplicação dos documentos de patentes, os tipos de depositantes, bem como o número de patentes depositadas por residentes e não residentes.

\section{RESULTADOS E DISCUSSÃO}

Através da pesquisa utilizando a Classificação Internacional de Patentes (CIP) e as palavras-chaves selecionadas na base de dados do INPI, foi encontrado um universo de dados que correspondeu a 162 documentos de patentes, entretanto, após a análise foram selecionados 142 documentos para compor o escopo dos resultados deste mapeamento tecnológico, considerados assim como relevantes para a pesquisa. Os 20 documentos foram excluídos porque durante a pesquisa utilizando as palavras-chave "mel and abelha" foram recuperados documentos que faziam referências a dispositivos que apenas tinha a sua estrutura na forma de favo de mel, não sendo consideradas relevantes para compor o escopo de resultados dessa pesquisa.

Destaca-se que as patentes são consideradas como o instrumento de proteção mais utilizado na área de inovação tecnológica. Sua importância é fundamental, pois a concessão deste direito de exclusividade garante ao seu titular a possibilidade de retorno do investimento aplicado no desenvolvimento de novos produtos e processos industriais. No Brasil, de acordo a Lei da Propriedade Industrial (LPI 9279/96) as patentes podem ser classificadas como Patente de Invenção (PI) ou Modelo de Utilidade (MU), a depender do seu escopo de desenvolvimento ou aperfeiçoamento tecnológico. Nesta pesquisa, do total de documentos de patentes encontrados, 115 documentos correspondiam como Patentes de Invenção (PI) e 26 como Modelo de Utilidade (MU). Foi identificado ainda um documento classificado como Certificado de Adição. De acordo com o

Cadernos de Prospecção - ISSN 1983-1358 (print) 2317-0026 (online), 2013, vol.6, n.1, p.45-55.

D.O.I.: http://dx.doi.org/10.9771/S.CPROSP.2013.001.006 
artigo 76 da LPI, o depositante do pedido ou titular de patente de invenção poderá requerer o certificado de adição para proteger aperfeiçoamento ou desenvolvimento introduzido no objeto da invenção, mesmo que destituído de atividade inventiva, desde que a matéria se inclua no mesmo conceito inventivo.

O mel é usado pelo homem como alimento e por suas propriedades terapêuticas desde a préhistória. Por vários séculos, foi retirado dos enxames de forma extrativista e predatória, muitas vezes causando danos ao meio ambiente, matando as abelhas. Entretanto, com o tempo, o homem foi aprendendo a proteger seus enxames, instalá-los em colmeias racionais e manejá-los de forma que houvesse maior produção de mel sem causar prejuízo para as abelhas. Nascia, assim, a apicultura (CAMARGO et al., 2003).

Em relação à origem tecnológica do mel sob a solicitação de proteção por meio dos direitos de propriedade industrial no Brasil, mais especificamente como patente, a primeira patente identificada foi depositada em 01 de agosto de 1984, tendo como país de origem do depositante o Brasil. A primeira patente identificada tem como título "Favo" e faz referência a um dispositivo utilizado para proporcionar redução de tempo de extração do mel para o apicultor. A partir da coleta de informações quanto à data de depósito de todos os documentos selecionados, foi elaborado o gráfico da Figura 1, que apresenta a evolução anual de depósitos de patentes relacionadas à produção e utilização do mel e tecnologias correlatas, depositadas no Brasil, em diferentes áreas tecnológicas, entre 1984 e 2011.

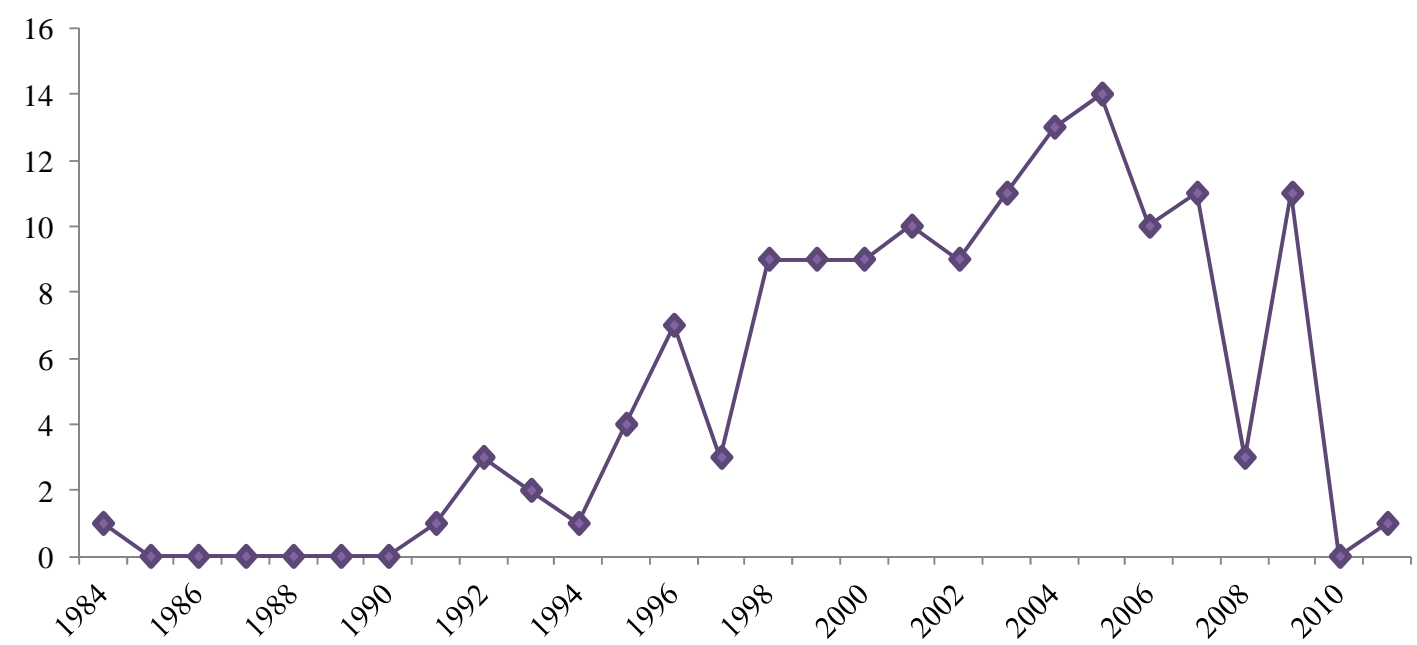

Figura 1: Evolução anual de depósitos de patentes no Brasil sobre o mel e tecnologias correlatas entre 1984 e 2011. Fonte: Autoria própria, 2012.

Através da análise dos documentos de patentes foi identificado que, entre os anos de 1984 e 1994, tem-se o depósito de pedidos relacionados ao mel aplicados principalmente na indústria de alimentos e elaboração de dispositivos utilizados na apicultura. Após esse período, ou seja, a partir de 1995, começam a surgir as patentes relacionadas às aplicações do mel em outras áreas tecnológicas, como na indústria farmacêutica (fármacos e cosméticos), agronomia, veterinária e 
processos químicos, tendo diferentes países como depositantes. Além disso, foi observado nesse período o maior número dos Modelos de Utilidade encontrados, que correspondem a aperfeiçoamentos constituídos de ato inventivo para equipamentos e dispositivos apícolas. Ressaltase que no ano de 2010 não foi identificado nenhum documento de patente, e em 2011 foi identificado apenas um documento. Entretanto, é importante destacar que não podemos considerar esse número como os verdadeiros valores de proteção, tendo em vista o período de sigilo que é de 18 meses. Assim, certamente novas tecnologias foram protegidas nestes anos (2010 e 2011), porém, não serão citadas e computadas nesta pesquisa devido ao período de sigilo.

A partir da análise dos documentos de patentes depositados no Brasil e selecionados nesta pesquisa sobre o mel e tecnologias correlatas, no que diz respeito ao país/região onde se originou a tecnologia patenteada, é possível constatar que a maior parte do depósito é feito por residentes, $78,87 \%$, enquanto não residentes possuem $21,13 \%$ dos documentos depositados em relação à tecnologia de interesse. É importante destacar que essa análise foi feita através da identificação do país/região de origem do depositante. A Figura 2 relaciona o número de documentos de patentes depositados no Instituto Nacional de Propriedade Industrial (INPI) por país/região de origem, ou seja, país/região de origem do depositante da patente, que não estão em sigilo até o momento da pesquisa.

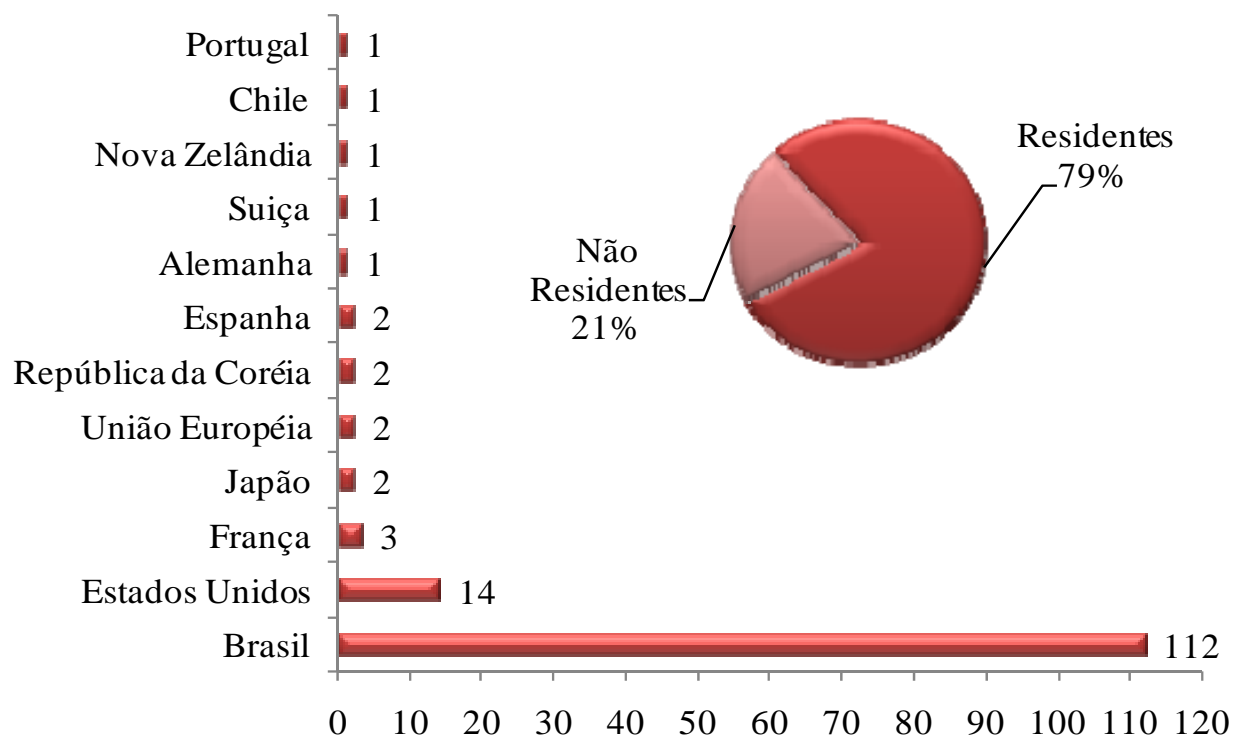

Figura 2: Distribuição de depósitos dos documentos de patentes relacionadas ao mel e tecnologias correlatas por país/região de origem dos depositantes entre 1984 e 2011 (residentes e não residentes). Fonte: Autoria própria, 2012.

O Brasil é o país responsável pelo maior número de depósitos de patentes nas áreas de produção e aplicações do mel, com 112 documentos de patentes depositados, seguido pelos Estados Unidos, com 14 patentes depositadas. A partir da análise dos documentos de patentes de não residentes (21,13\%), identificou-se um total de depósitos realizados por 11 diferentes países/regiões. O Brasil 
é considerado atualmente como um país com forte potencial para a produção dos produtos apícolas, incluindo, por exemplo, o mel. Atualmente o Brasil ocupa a posição de $11^{\circ}$ colocado no ranking de produção mundial do mel, sendo o $5^{\circ}$ em exportação. Apesar dessa posição de destaque como país produtor e exportador, o pequeno número de depósitos de patentes por outros países no Brasil (não residentes) evidencia que este não é considerado como um mercado de interesse para a proteção dessa tecnologia (mel e tecnologias correlatas).

De acordo com a Figura 2, o Brasil tem 112 patentes depositadas que fazem referência ao mel. Com o objetivo de analisar o potencial tecnológico nacional em relação aos estados brasileiros, foi feita uma avaliação de quais estados são depositantes e detentores dessa tecnologia. A Figura 3 revela o número de documentos de patentes depositados pelos estados brasileiros que não estavam em sigilo até o momento da pesquisa.

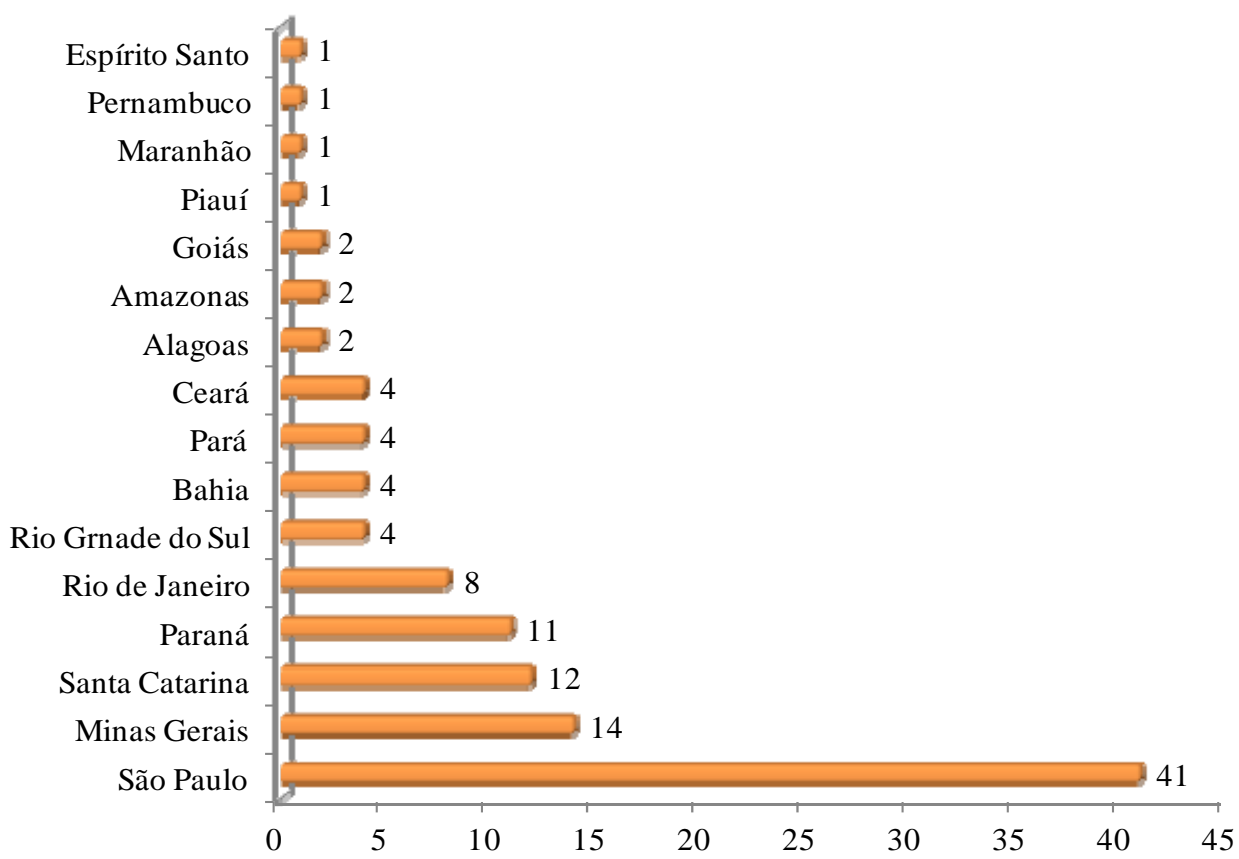

Figura 3: Distribuição de depósitos dos documentos de patentes no Brasil relacionadas ao mel e tecnologias correlatas por estado brasileiro. Fonte: Autoria própria, 2012.

Em relação às patentes nacionais, 16 estados brasileiros são detentores da tecnologia pesquisada. São Paulo é o estado que possui o maior número de patentes depositadas, seguido de Minas Gerais e Santa Catarina, com 41, 14 e 12 patentes, respectivamente, sendo que a maioria destas patentes foi depositada por inventores independentes.

A partir de dados fornecidos pelo IBGE (Instituto Brasileiro de Geografia e Estatísticas), a produção nacional de mel em 2010 foi de 38 mil toneladas, e a região Sul do país foi responsável pela maior produção do total nacional. A região Sul produziu em 2010 16,53 mil toneladas de mel, o que corresponde a 43\%. A região Nordeste, por sua vez, totalizou uma produção de 13,1 mil 
toneladas de mel. Destaca-se ainda que os cinco maiores estados produtores de mel do Brasil são Rio Grande do Sul, Paraná, Santa Catarina, Piauí e Minas Gerais, totalizando quase 70\% da produção nacional.

A partir dos resultados apresentados na Figura 3 é possível observar que apesar do estado de São Paulo ocupar a $7^{\mathrm{a}}$ posição no ranking dos maiores produtores de mel do Brasil (Figura 3), é o que possui a maior capacidade tecnológica, ou seja, conhecimento técnico e científico para transformar essa matriz de origem animal em produtos e/ou processos passíveis de proteção pela propriedade industrial. Com base nas informações fornecidas pelo MCTI (Ministério de Ciência, Tecnologia e Inovação) no que diz respeito aos investimentos em P\&D (Pesquisa \& Desenvolvimento) por estado brasileiro, constata-se que o estado de São Paulo é o que possui os maiores investimentos em P\&D quando somados os investimentos federais com os estaduais. A P\&D é definida como aquelas atividades dirigidas para a busca de conhecimento científico e tecnológico novo ou à aplicação de conhecimentos existentes de uma nova forma. Os investimentos em P\&D são excelentes indicadores para avaliar o potencial tecnológico de um país/região, visto que, na maioria das vezes, quanto maior é o investimento nessa área estratégica, maior é o número de patentes (ou outros intangíveis da propriedade industrial) depositados por este país/região. Além disso, no Manual de Frascati (2002) elaborado pela OCDE (Organização para Cooperação Econômica e Desenvolvimento), as patentes são consideradas como indicadores de inovação.

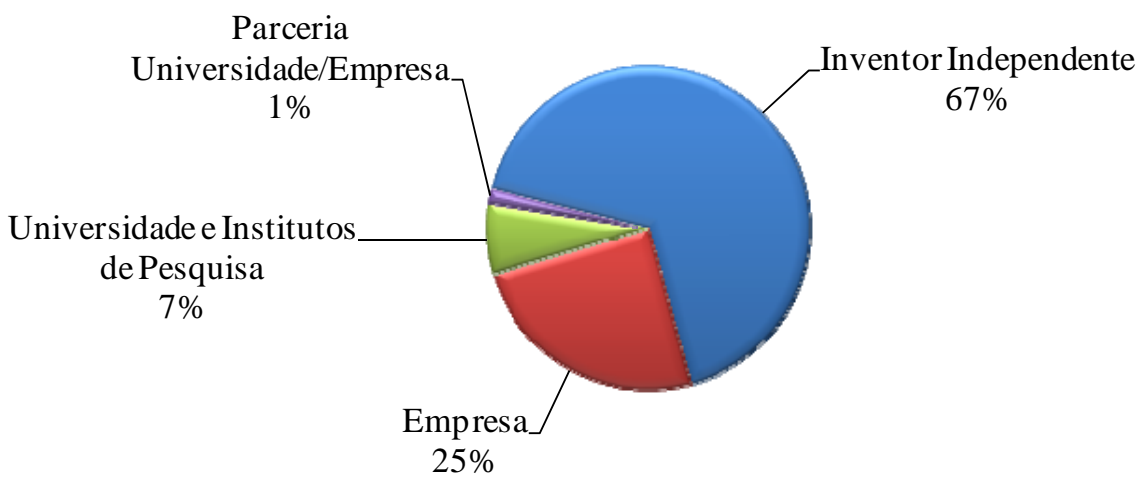

Figura 4: Distribuição dos documentos de patentes relacionados ao mel e tecnologias correlatas depositadas no Brasil entre os anos de 1984 e 2011 por tipo de depositante. Fonte: Autoria própria, 2012.

A análise do tipo de depositante é extremamente importante em estudos de monitoramento tecnológico com o interesse de avaliar onde se encontram concentrados os investimentos em P\&D responsáveis por gerar inovação. A partir do levantamento de dados nos documentos de patentes analisados neste estudo, os depositantes dos documentos de patentes foram classificados em quatro tipos: (1) Empresa - quando o depositante estava relacionado com o setor industrial (pessoa jurídica); (2) Independente - quando o depositante era uma pessoa física, sendo na maioria dos casos o próprio inventor; (3) Universidade - quando o depositante era uma universidade (pública ou 
privada) ou institutos de pesquisa; e (4) Parceria Universidade Empresa - quando existia cotitularidade entre as partes como depositante. A Figura 4 apresenta o total de patentes depositadas no Brasil para cada tipo de depositante. Do total de documentos de patentes depositados entre os anos de 1984 e 2011, mais da metade dos pedidos foram solicitados por inventores independentes, representado por 66,90\% desses pedidos, seguido de pedidos por empresas, $24,64 \%$ e universidade e institutos de pesquisa, com 7,04\%.

A partir desses resultados, é possível constatar que as pesquisas tecnológicas referentes à tecnologia pesquisada estão em menor proporção protegidas pelas universidades e empresas. Para que ocorra o aumento do depósito de patentes pelas universidades nacionais na área pesquisada, e nas demais áreas tecnológicas, é necessário que os pesquisadores nacionais adotem o conhecimento da propriedade industrial e passem a proteger as suas pesquisas por meio de patentes (ou outros intangíveis da propriedade industrial) antes da publicação de artigos em revistas científicas. Para o que o Brasil se torne um país que tenha potencial para gerar inovação nas diferentes áreas tecnológicas, é extremamente importante e necessário que os alunos de graduação, pós-graduação e os professores tenham o conhecimento básico da importância e definições da propriedade industrial. Só a partir disto, as universidades se tornarão fortes criadores de intangíveis. A Figura 5 apresenta as universidades que possuem patentes depositadas no Brasil na área pesquisada.

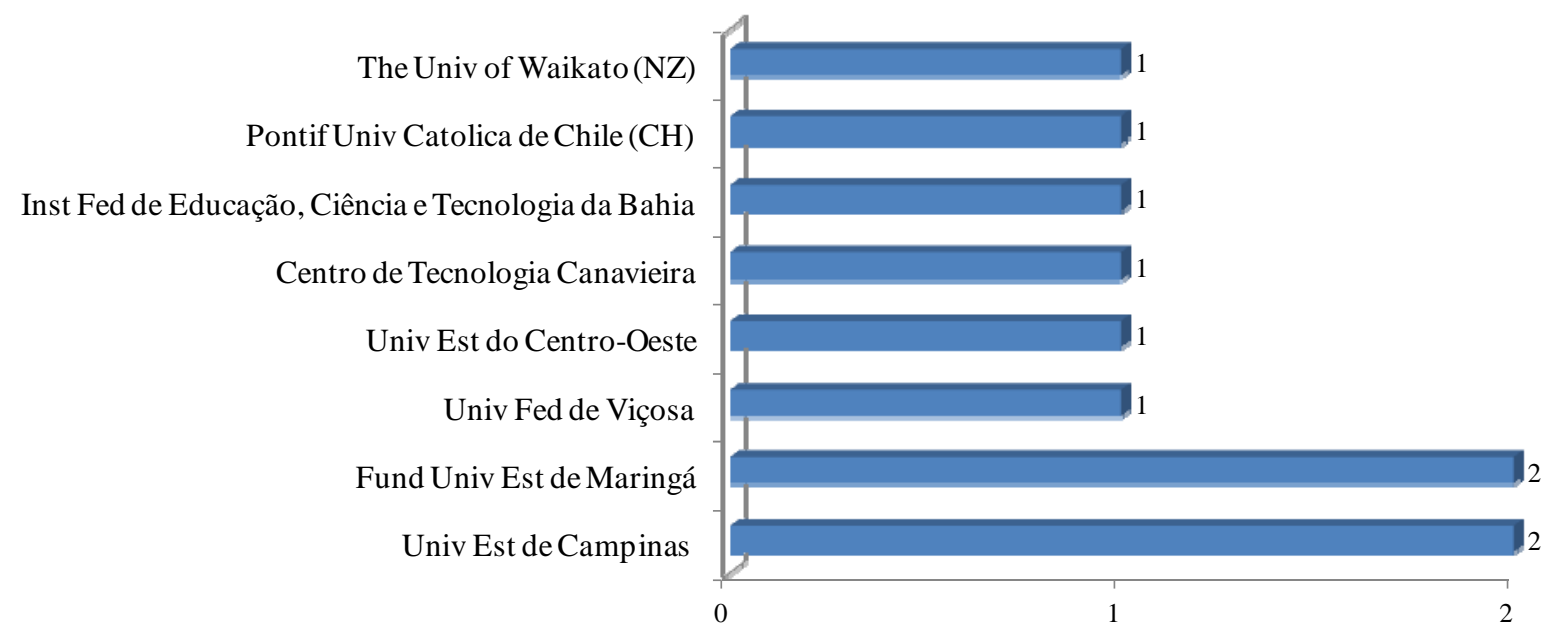

Figura 5: Distribuição dos documentos de patentes relacionados ao mel e tecnologias correlatas depositados no Brasil por Universidade entre 1984 a 2011. Fonte: Autoria própria, 2012.

A partir da CIP (Classificação Internacional de Patentes) foi possível determinar as principais áreas de aplicação que envolvem o mel e tecnologias correlatas. A Figura 6 revela a distribuição das principais áreas tecnológicas de aplicação do mel. Do volume total de documentos, 32,39\% estão relacionados à área de Indústria de Alimentos (Alimentos e Bebidas), 30,98\% relacionados a dispositivos e equipamentos apícolas, 21,83\% relacionados à indústria farmacêutica (medicamentos e cosméticos), entre outros, conforme se pode verificar na Figura 6. 


\section{CONCLUSÕES}

O mel é um produto apícola de origem animal que tem apresentado uma demanda crescente de mercado nos últimos anos, com o Brasil ocupando um lugar de destaque na produção e exportação deste produto. A partir do mapeamento tecnológico realizado neste estudo, percebe-se que essa matriz está sendo utilizada para o desenvolvimento de produtos e processos em diferentes áreas tecnológicas. O Brasil ainda é um país de pouco interesse para a proteção da tecnologia na área pesquisada, evidenciado através do pequeno número de patentes de não residentes. Para fortalecer o sistema de inovação do país são necessários, portanto, mais incentivos governamentais que possam apoiar as pesquisas nessa área, tendo em vista a produção de novas tecnologias que possam ser protegidas por patentes, visto que as patentes são consideradas pelo Manual de Frascati como indicadores de inovação.

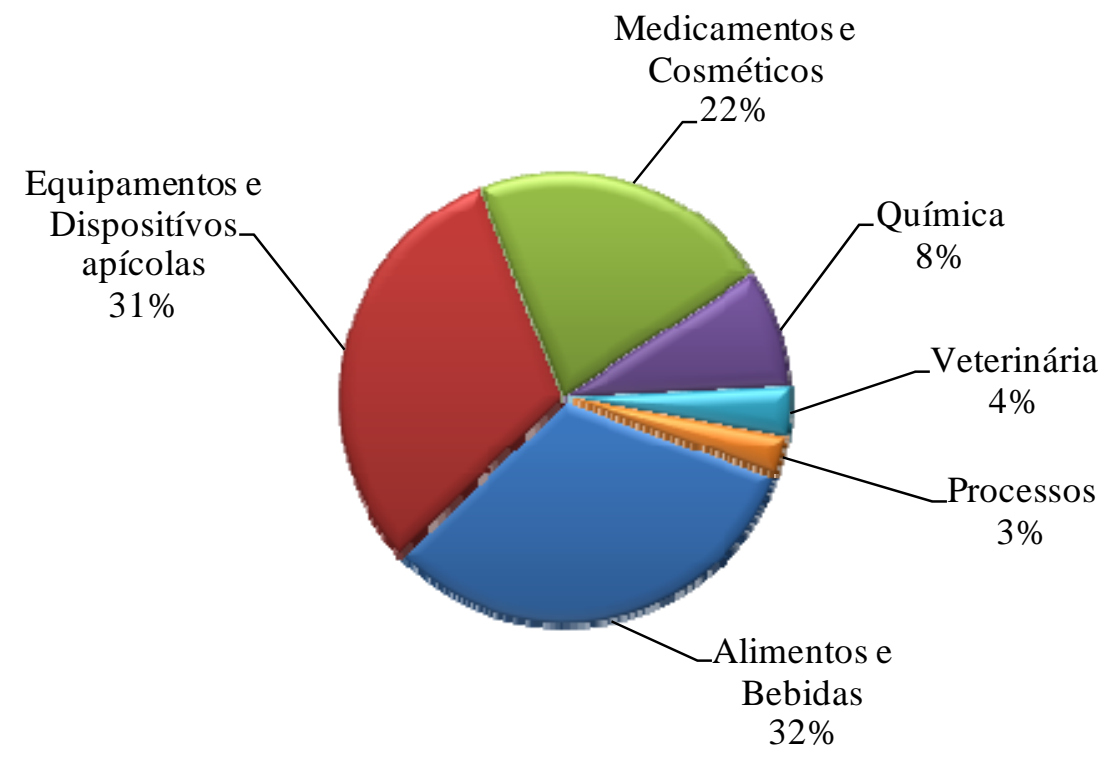

Figura 6: Distribuição dos documentos de patentes relacionados ao mel e tecnologias correlatas depositadas no Brasil por área de aplicação. Fonte: Autoria própria, 2012.

\section{REFERÊNCIAS}

AROUCHA, E. M. M.; OLIVEIRA, A. L. J.; NUNES, G. H. S.; MARACAJÁ, P. B.; SANTOS, M. C. A. Qualidade do mel de abelha produzidos pelos incubados da iagram e comercializado no municipio de mossoró/RN. Revista Caatinga, v. 21, n. 1, p. 211-217, 2008.

BRASIL. Ministério da Agricultura, Pecuária e Abastecimento. Legislação de Produtos Apícolas e Derivados. Instrução Normativa n. 11, de 20 de outubro de 2000. Regulamento técnico de identidade e qualidade do mel. Disponível em: <http://www.agricultura.gov.br>. Acessado em: 00 out. 2012.

CAMARGO, R. C. R. de; PEREIRA, F. de M.; LOPES, M. T. do R.; WOLFF, L. F. Mel: características e propriedades. Terezina: EMBRAPA Meio-Norte, 2006. 28p. 
CODEX STANDARD FOR HONEY. Revised codex standard for honey codex stan 12-1981 Disponível em: <http://www.ipfsaph.org/id/codexCodexstan12>. Acessado em: 00 out. 2012.

CRANE, E. A book of honey. Oxford: Oxford University Press, 1980. 193p.

GARCIA, A. La miel de abejas. Composicion química, propiedades y usos industriales. Revista Chilena de Nutricion, v. 14, n. 13, p. 183-191, 1986.

MARCHINI, L. C.; GENI, S. S.; MORETI, A. C. de C. C. Mel Brasileiro: Composição e normas. Ribeirão Preto: A. S. Pinto, 2004. 111p.

MENDES, C. G.; SILVA, J. B. A.; MESQUITA, L. X.; MARACAJÁ, P. B. As analises do mel: revisão. Revista Caatinga, v.22, n. 2, p. 07-14, 2009.

PEREIRA, F. de M.; LOPES, M. T. do R.; CAMARGO, R. C. R. de; VILELA, S. L. de O. Produção de mel. Embrapa Meio-Norte, versão virtual. 2003. Disponível em: $<$ http://sistemasdeproducao.cnptia.embrapa.br/FontesHTML/Mel/SPMel/index.htm>. Acessado em: 00 out. 2012.

PEROSA, J. M. Y.; ARAUCO, E. M. R.; SANTOS, M. L. de. A.; ALBARRACIN, V. N. Parâmetros de competitividade do mel brasileiro. Informações Econômicas, v. 34, n. 3, p. 42-48, 2004.

SEBRAE, Serviço Brasileiro de Apoio às micros e pequenas empresas. Apicultura: exportações. Disponível em: <http://www.sebrae.com.br>. Acessado em: 00 out. 2012.

WHITE, J. W. Quality control for honey enterprises in less developed areas: an Indonesian example. Bee world, v. 69, n. 2, p. 49-62, 1988. 